\title{
Amphiphilic branched polymer-nitroxides conjugate as a nanoscale agent for potential magnetic resonance imaging of multiple objects in vivo
}

Xiaoming Wang ${ }^{1,3 \dagger}$, Shiwei Guo ${ }^{4,5 \dagger}$, Zhiqian Li ${ }^{1}$, Qiang Luo ${ }^{1}$, Yan Dai ${ }^{4,5}$, Hu Zhang ${ }^{6}$, Yun Ye ${ }^{4}$, Qiyong Gong ${ }^{1,2}$ and Kui LuO ${ }^{1,2^{*}}$

\begin{abstract}
Background: In order to address the potential toxicity of metal-based magnetic resonance imaging (MRI) contrast agents (CAs), a concept of non-metallic MRI CAs has emerged. Currently, paramagnetic nitroxides (such as (2,2,5,5-tetramethylpyrrolidine-1-oxyl, PROXYL), (2,2,6,6-tetramethylpiperidine-1-oxide, TEMPO), etc.) are being extensively studied because their good stability and imaging mechanism are similar to metal-based contrast agents (such as $\mathrm{Gd}^{3+}$ chelate-based clinical CAs). However, a lower relaxivity and rapid in vivo metabolism of nitroxides remain to be addressed. Previous studies have demonstrated that the construction of macromolecular nitroxides contrast agents (mORCAs) is a promising solution through macromolecularization of nitroxides (i.e., use of large molecules to carry nitroxides). Macromolecular effects not only increase the stability of nitroxides by limiting their exposure to reductive substances in the body, but also improve the overall ${ }^{1} \mathrm{H}$ water relaxation by increasing the concentration of nitroxides and slowing the molecular rotation speed.
\end{abstract}

Results: Branched pDHPMA-mPEG-Ppa-PROXYL with a high molecular weight ( $\mathrm{MW}=160 \mathrm{kDa}$ ) and a nitroxides content $(0.059 \mathrm{mmol} / \mathrm{g})$ can form a nanoscale $(\sim 28 \mathrm{~nm})$ self-assembled aggregate in a water environment and hydrophobic PROXYL can be protected by a hydrophilic outer layer to obtain strong reduction resistance in vivo. Compared with a small molecular CA (3-Carboxy-PROXYL (3-CP)), Branched pDHPMA-mPEG-Ppa-PROXYL displays three prominent features: (1) its longitudinal relaxivity $\left(0.50 \mathrm{mM}^{-1} \mathrm{~s}^{-1}\right)$ is about three times that of $3-\mathrm{CP}\left(0.17 \mathrm{mM}^{-1} \mathrm{~s}^{-1}\right)$; (2) the blood retention time of nitroxides is significantly increased from a few minutes of 3-CP to 6 h; (3) it provides long-term and significant enhancement in MR imaging of the tumor, liver, kidney and cardiovascular system (heart and aortaventralis), and this is the first report on nitroxides-based MRI CAs for imaging the cardiovascular system.

\footnotetext{
*Correspondence: luokui@scu.edu.cn

${ }^{\dagger}$ Xiaoming Wang and Shiwei Guo contributed equally to this study

1 Huaxi MR Research Center (HMRRC), Department of Radiology,

National Clinical Research Center for Geriatrics, Frontiers Science

Center for Disease-Related Molecular Network, State Key Laboratory

of Biotherapy, West China Hospital, Sichuan University, 610041 Chengdu,

China

Full list of author information is available at the end of the article
}

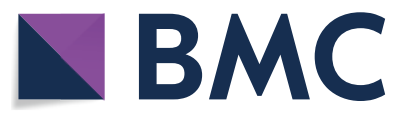

(c) The Author(s) 2021. This article is licensed under a Creative Commons Attribution 4.0 International License, which permits use, sharing, adaptation, distribution and reproduction in any medium or format, as long as you give appropriate credit to the original author(s) and the source, provide a link to the Creative Commons licence, and indicate if changes were made. The images or other third party material in this article are included in the article's Creative Commons licence, unless indicated otherwise in a credit line to the material. If material is not included in the article's Creative Commons licence and your intended use is not permitted by statutory regulation or exceeds the permitted use, you will need to obtain permission directly from the copyright holder. To view a copy of this licence, visit http://creativeco mmons.org/licenses/by/4.0/. The Creative Commons Public Domain Dedication waiver (http://creativecommons.org/publicdomain/ zero/1.0/) applies to the data made available in this article, unless otherwise stated in a credit line to the data. 
Conclusions: As a safe and efficient candidate metal-free magnetic resonance contrast agent, Branched pDHPMAmPEG-Ppa-PROXYL is expected to be used not only in imaging the tumor, liver and kidney, but also the cardiovascular system, which expands the application scope of these CAs.

Keywords: Metal-free contrast agents, Nitroxides, Magnetic resonance imaging, Polymers

\section{Introduction}

Magnetic resonance imaging (MRI) is a very effective medical imaging technology which has been widely used in the clinical diagnosis of many diseases [1-3]. However, conventional MRI examinations often have insufficient image contrast, so a higher amount of MRI contrast agents need to be applied to patients to obtain clearer and more accurate diagnostic results [4-7]. At present, metal-based MRI contrast agents (CAs) are commonly used clinically, including paramagnetic $\mathrm{Gd}^{3+}$ chelates ( $\mathrm{T} 1$, positive contrast agents) and superparamagnetic $\mathrm{Fe}_{3} \mathrm{O}_{4}$ nanoparticles (T2, negative contrast agents) [8-11]. Unfortunately, both of them have safety risks. [12-14]. Therefore, it has become a research hotspot to address the toxicity of metal-based MRI CAs.

In this process, a concept of non-metallic MRI CAs has emerged. Currently, paramagnetic nitrogen oxide radicals (nitroxides) (such as PROXYL, TEMPO, etc.) are being extensively studied because of their good stability and a similar imaging mechanism to metal-based contrast agents (such as $\mathrm{Gd}^{3+}$ chelate-based clinical CAs) [15-19]. However, there are some inherent obstacles of nitroxides that need to be overcome to use as clinical MRI CAs. First, the unpaired electrons (only one) of nitroxides are less than those of Gd(III) ions (seven), so the T1 relaxation efficiency $\left(r_{1}\right)$ of nitroxides are significantly lower than that of contrast agents based on Gd(III) ions. In addition, due to the reducible sensitivity, nitroxides will be quickly converted into non-relaxing nitrohydroxyl compounds by the reductive substances in the body [20-24], resulting in loss of paramagnetism, which leads to their short half-life and an insufficient window time for MR imaging. Previous studies [25-29] have demonstrated that the construction of macromolecular nitroxides-based contrast agents (mORCAs) is a promising solution via macromolecularization of nitroxides, or use of large molecules to carry nitroxides. The macromolecular effect not only enhances the stability of nitroxides by limiting their exposure to reductive substances in the body, but also improves the overall ${ }^{1} \mathrm{H}$ water relaxation by increasing the concentration of nitroxides and slowing the molecular rotation speed [27, 30-33]. However, these mORCAs have not obtained ideal results. They mainly face two challenges to be addressed: (1) relaxivities and in vivo imaging durations need to be further improved; (2) biosafety of macromolecular materials [34]. In the early stage, we used linear and cross-linked biodegradable PEGylated polyester to construct two novel mORCAs which have made unprecedented achievements in solving the above two problems, and the cross-linked one was the most outstanding [35]. Although the above studies have not completely solved the problems faced by mORCAs, it has injected great expectation and hope into the research field. Therefore, it is necessary to develop more macromolecular carrier materials for constructing more mORCAs in order to develop efficacious metal-free MRI CAs.

Among macromolecular carriers, biodegradable poly[ $N$-(1,3-dihydroxypropyl) methacrylamide] (DHPMA copolymers) are favored due to their great structure controllability, diversified functions, long-term blood circulation, excellent water solubility, non-immunogenicity and good biosafety [36-41]. These copolymers have been successfully employed for the development of metal-based macromolecular CAs (mCAs) [30, 42, 43]. Therefore, it is expected that the combination of small molecular nitroxide radicals with biodegradable DHPMA copolymers could result in safe and efficient metal-free MRI mCAs. These copolymers help nitroxides to improve the relaxivity in vitro and accumulation of nitroxides in some tissues and organs in vivo, thereby generating a multiplication effect to achieve improvement in the imaging contrast. Meanwhile, these DHPMA copolymers have been demonstrated to display low side effects [44].

In this study, we designed and synthesized a novel nitroxide radicals-based mCA, Branched pDHPMAmPEG-Ppa-PROXYL, which was derived from an enzyme/GSH sensitive PEGylated branched DHPMA copolymer as the macromolecular skeleton. Amphiphilic Branched pDHPMA-mPEG-Ppa-PROXYL could self-assembly into nano-sized aggregates in an aqueous environment. As shown in Fig. 1, the hydrophilic components formed the outer layer to encapsulate hydrophobic nitroxides (PROXYL) inside, thereby enhancing the stability of PROXYL. Enhanced stability combined with the macromolecular effects, including long blood circulation, increased nitroxides concentration and slow molecular rotation, rendered this nitroxides-based metal-free mCA to be used for MR imaging of multiple targets in vivo including tumor, liver, kidney and cardiovascular system (heart and aortaventralis). In 


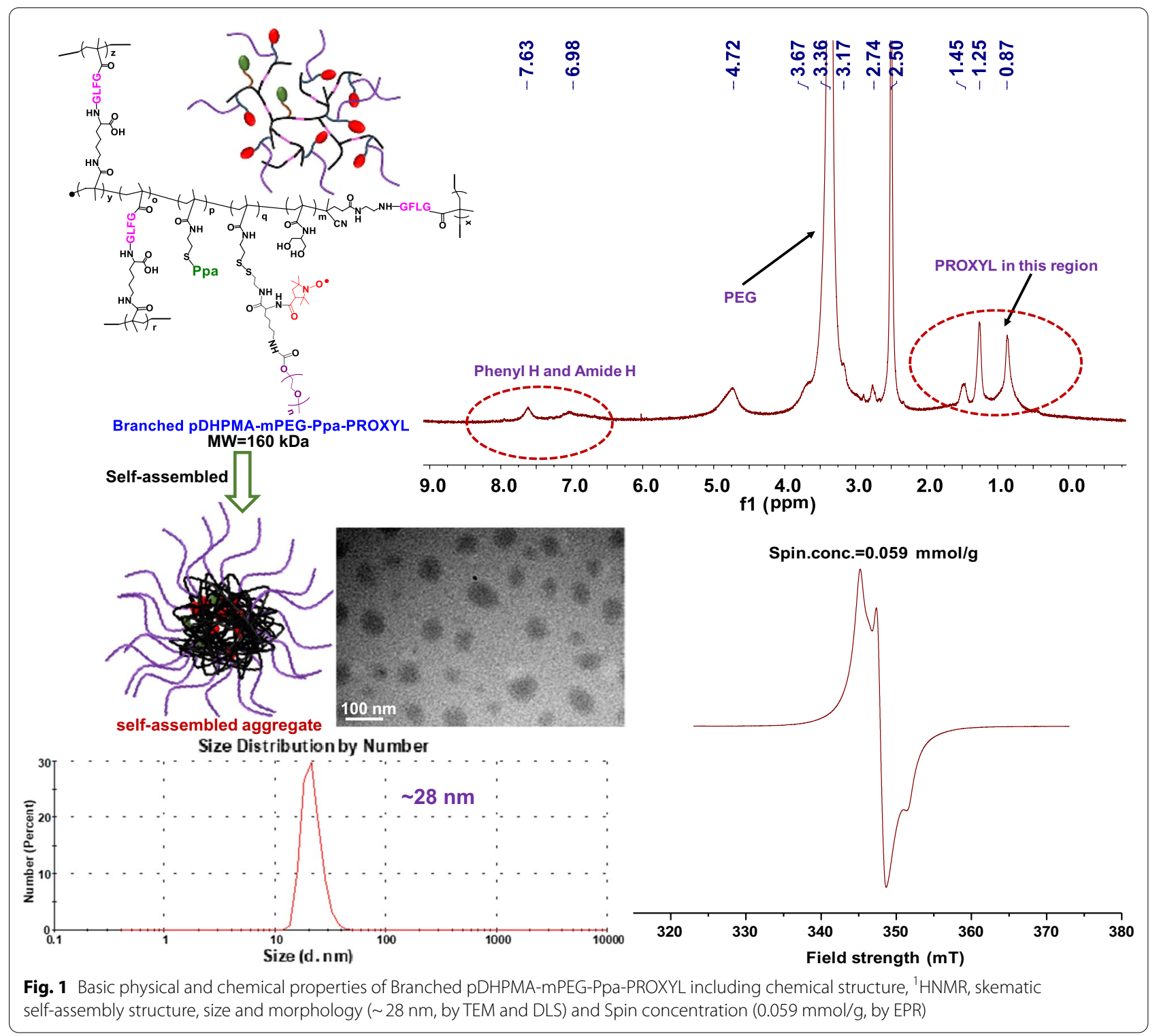

particular, to our knowledge, this is the first report on nitroxides-based MRI CAs for imaging the cardiovascular system.

\section{Materials and methods}

Materials, methods, synthesis of the PROXYLbased branched biodegradable mORCA (Branched pDHPMA-mPEG-Ppa-PROXYL, Additional file 1: Scheme S1) and its characterizations (Additional file 1: Table S1) were supplemented in the Supporting Information. In vitro or vivo toxicity, blood compatibility test and cell uptake experiment methods were also placed in the Supporting Information.

\section{Animal and tumor models}

All animals were fed in a control room. $7 \times 10^{5} 4 \mathrm{~T} 1$ cells were inoculated subcutaneously in the dorsal side of each mouse. When the tumor reached $100 \mathrm{~mm}^{3}$, all experimental mice were randomly divided for MR imaging and other experimental studies.

\section{In vitro relaxivity and in vivo MR imaging}

The longitudinal relaxivity of Branched pDHPMAmPEG-Ppa-PROXYL in phosphate buffer saline (PBS) was measured using a clinical Siemens 3.0 T MRI scanner. Branched pDHPMA-mPEG-Ppa-PROXYL at different concentrations of PROXYL $(0,0.17,0.34,0.68$, 
1.35, 2.7, 5.4, $10.8 \mathrm{mM}$ ) was dissolved in $0.1 \mathrm{M} \mathrm{PBS,}$ and MR signals of the prepared solutions were scanned by $\mathrm{T} 1 \mathrm{SE}$ sequence with scanning parameters: $\mathrm{TE}=6.9$ $\mathrm{ms}, \mathrm{TR}=20,30,50,70,90,125,150,175,200,300,400$, $500,700,850$, and $1000 \mathrm{~ms}$, Fov $=200 \mathrm{~mm}$, slice thickness $=1.0 \mathrm{~mm}$, and matrix dimensions $=256 \times 256$. The corresponding $1 / \mathrm{T} 1$ values were obtained from their T1-weighted MR images. The value of relaxivity $\left(r_{1}\right)$ was calculated by plotting $1 / \mathrm{T} 1$ as a function of different PROXYL concentrations. In addition, 3-Carboxy-PROXYL (3-CP) at the same concentration in $0.1 \mathrm{M}$ PBS was used as a control.

Twenty 8-10 weeks healthy female BALB/c mice were randomly divided into four groups $(5$ in each group, $20 \pm 2 \mathrm{~g}$ ). Another ten female BALB/c mice of tumor-bearing ( $20 \pm 2 \mathrm{~g}, 8-10$ weeks) were also randomly divided into two groups $(\mathrm{n}=5)$. The MR signals of main organs (heart, liver and kidney), aortaventralis and tumor in the body at different time points were obtained via a clinical Siemens 3.0 T MRI scanner. A mouse coil was employed (Shanghai Chenguang Medical Technology Co., Ltd., model: CG MUC23 H300 AS with an eight-channel phased array structure), and the $\mathrm{T}_{1}$ mapping sequence was used for coronal scanning. The scan sequence was: $\mathrm{TR}=15 \mathrm{~ms}, \mathrm{TE}=2.04 \mathrm{~ms}$, flip angle $=5^{\circ} / 26^{\circ}$, slices $=10$, slice space $=0.4 \mathrm{~mm}$, thickness $=2.0 \mathrm{~mm}$, and Fov $=156 \times 156 \mathrm{~mm}$. Scanning was executed at pre-injection, $5,10,15,20,25$, and $30 \mathrm{~min}$ after the injection of Branched pDHPMA-mPEGPpa-PROXYL and 3-CP at a dose of $0.135 \mathrm{mmol} / \mathrm{kg}$ PROXYL to obtain images of each organ, aortaventralis and tumor. The MATLAB software $[45,46]$ was used to analyze the $T_{1}$ values of each organ, aortaventralis and tumor before and after enhancement.

\section{In vivo metabolism}

Ten female healthy BALB/c mice (8-10 weeks, $20 \pm 2 \mathrm{~g})$ were randomly divided into two groups $(\mathrm{n}=5)$, and Branched pDHPMA-mPEG-Ppa-PROXYL and 3-CP were injected through the tail vein at a dose of $0.135 \mathrm{mmol} / \mathrm{kg}$ PROXYL, respectively. $50 \mu \mathrm{L}$ of blood samples were collected through the fundus vein at time points of $3 \mathrm{~min}, 6 \mathrm{~min}, 9 \mathrm{~min}, 12 \mathrm{~min}, 15 \mathrm{~min}$, $30 \mathrm{~min}, 1 \mathrm{~h}, 2 \mathrm{~h}, 4 \mathrm{~h}, 8 \mathrm{~h}$, and $24 \mathrm{~h}$ after injection. The blood samples were centrifuged $(10,000 \mathrm{~g} \times 5 \mathrm{~min})$ and the serum supernatants were collected. The spin concentration (the nitroxides content) of each serum sample at different time points was measured by electronic paramagnetic resonance (EPR).

\section{Results and discussion}

\section{Preparation and characterization of Branched} pDHPMA-mPEG-Ppa-PROXYL

According to our previous studies, Gd(III)-based mCAs constructed from DHPMA copolymers with a branched structure could make full use of the macromolecular effect to achieve high relaxivities and great in vivo MR imaging. Therefore, in this study, we prepared a branched DHPMA copolymer whose each branched chain contains an enzyme sensitive GFLG peptide for the construction of a novel biodegradable branched PROXYL-based mORCA (Branched pDHPMA-mPEG-Ppa-PROXYL, as shown in Additional file 1: Scheme S1) in the hope of effectively improving the relaxivity and in vivo MR imaging of PROXYL via significant macromolecular effect. In addition, its detailed characterization is listed in Additional file 1: Table S1.

Firstly, we prepared a PEGylated PROXYL derivative functionalized by dithiopyridyl (PTE) (PTE-mPEGPROXYL, as shown in Additional file 1: Scheme S1) in a similar method we reported [35], and PTE-mPEGPROXYL has the following functions: (1) the PTE groups can react with thiols (thiol-disulfide exchange reaction) to covalently introduce PROXYL derivatives onto the macromolecular material, forming the corresponding mORCA; (2) Due to strong hydrophobicity of PROXYL, its introduction will weaken the water solubility of the mORCA, so we adopted PEGylation to balance hydrophobicity and hydrophilicity in the structure. PTEmPEG-PROXYL contains the same amount of $\mathrm{mPEG}_{2000}$ and PROXYL, therefore, after covalently connecting with the macromolecule, it can achieve a good water-solubility and obtain a higher content of PROXYL, so as to ensure full realization of the multiplier effect; (3) Additionally, PEGylation can further improve MW of the MORCA and enhance its biocompatibility and in vivo stability.

On the other hand, in our previous study, a branched DHPMA copolymer with a short enzyme-sensitive GFLG peptide in each branch chain (Branched pDHPMASH, as shown in Additional file 1: Scheme S1) was prepared via RAFT polymerization of DHPMA, PTEMA, MA-GFLGK-MA and MA-GFLG-NH-CTA induced by VA044. The Gd-based mCA derived from this copolymer displayed excellent relaxation performance both in vivo and in vitro, and also good biodegradability and low side effects [44]. Inspired by this result, we selected Branched pDHPMA-SH as a macromolecular carrier to construct a novel PROXYL-based mORCA (Branched pDHPMA-mPEG-Ppa-PROXYL, as shown in Additional file 1: Scheme S1). The synthesis process had two steps: 
(1) First, maleimide-functionalized pyropheophorbide- $\alpha$ (Ppa-Maleimide) as a fluorescent probe was covalently introduced via thiol-ene click chemistry, and the input quantity of Ppa-Maleimide did not exceed $1 \%$ of the total amount of raw material, which can meet the requirements of fluorescence imaging but does not affect the water solubility of the final copolymer; (2) Next, the PEGylated PROXYL derivative was covalently introduced via disulfide-thiol exchange reaction. The structure of the final copolymer was confirmed by ${ }^{1}$ HNMR (Additional file 1: Fig. S1), and gel permeation chromatography (GPC) measured its MW as $160 \mathrm{kDa}$ (Additional file 1: Table S1). EPR analysis showed that the copolymer had paramagnetism and the spin concentration (nitroxides content) was $0.059 \mathrm{mmol} / \mathrm{g}$ (Additional file 1: Fig. S2). According to our design ideas, Branched pDHPMAmPEG-Ppa-PROXYL has amphipathy and can selfassemble into an aggregate with a certain nanometer-size in water. We analyzed the particle size and morphology of the copolymer by dynamic light scattering (DLS) and transmission electron microscopy (TEM), and the results showed that Branched pDHPMA-mPEG-Ppa-PROXYL could form a self-assembled aggregate at a particle size of $28 \mathrm{~nm}$ (Additional file 1: Fig. S3-4). The amino acid analysis result (Additional file 1: Table S2) showed that the molar ratio of Gly/Phe/Leu was ca. 1.4/1.7/1, which indicated that the short peptide GFLG was introduced into the mORCA. Additionally, from DLS (Additional file 1: Fig. S5), the zeta potential of the final copolymer was ca. $0 \mathrm{mV}$, which indicated that the surface of Branched pDHPMA-mPEG-Ppa-PROXYL was electrically neutral, so it can prevent adsorption of proteins in the blood, resulting in a long retention time in the blood. All above chemical properties will result in good in vitro and in vivo performance of the mCA. First, its big molecular size and high content of nitroxides will help to improve the relaxivity via macromolecular effects including slow molecular rotation and accumulative effect. Second, it appears to be a stable amphiphilic nano-structure in aqueous environment, which is beneficial to enhance the in vivo stability of PROXYL by effective protection. The above two points, together with the inherent characteristics of macromolecules, make Branched pDHPMA-mPEG-PpaPROXYL very promising to produce excellent MR imaging effect in vivo.

\section{Relaxivity of Branched pDHPMA-mPEG-Ppa-PROXYL}

A clinical Siemens 3.0 T MRI scanner was used to measure the longitudinal relaxivity $\left(r_{1}\right)$ of Branched pDHPMA-mPEG-Ppa-PROXYL with 3-CP as a control. Bright signals were seen from the Branched pDHPMAmPEG-Ppa-PROXYL samples in MRI images, and these signals were more intense than those from $3-\mathrm{CP}$ at the

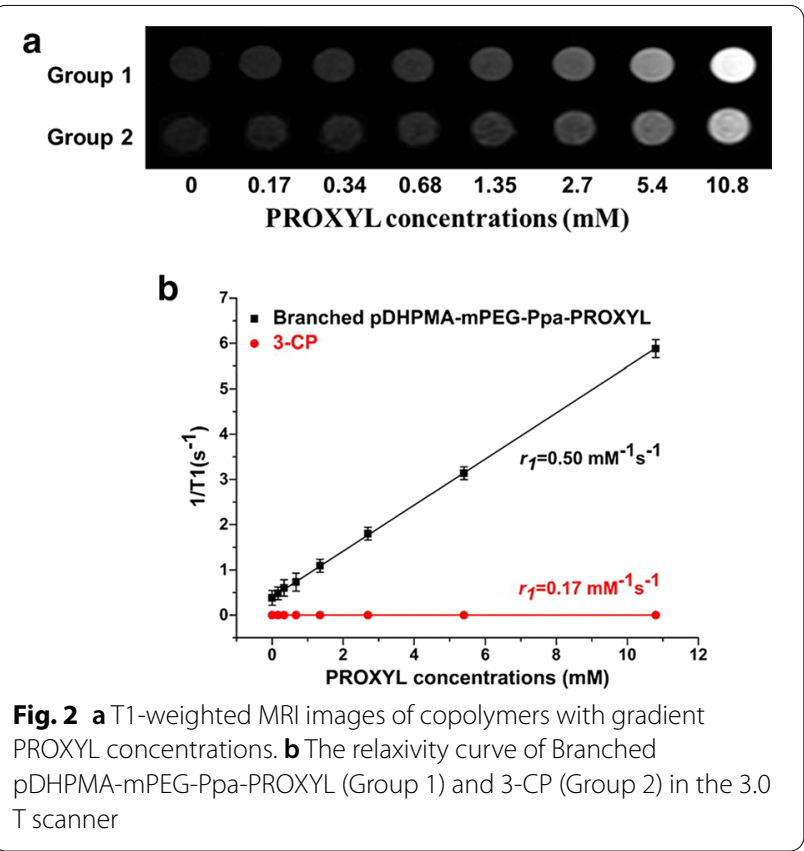

equivalent PROXYL concentration (Fig. 2a). As shown in Fig. $2 \mathrm{~b}$, the $r_{1}$ values were calculated by plotting $1 / \mathrm{T} 1$ with the gradient concentration of Branched pDHPMAmPEG-Ppa-PROXYL and 3-CP. The in vitro relaxation efficiency $\left(r_{1}=0.50 \mathrm{mM}^{-1} \mathrm{~s}^{-1}\right)$ of Branched pDHPMAmPEG-Ppa-PROXYL was significantly higher than that $\left(r_{1}=0.17 \mathrm{mM}^{-1} \mathrm{~s}^{-1}\right)$ of 3-CP.

\section{In vivo major organ and aortaventralis imaging}

A clinical 3T MRI scanner was used to detect MRI $\mathrm{T}_{1}$ mapping signals of Branched pDHPMA-mPEG-PpaPROXYL in living mice to evaluate its suitability as an MRI CA. A small molecule, 3-CP, was employed as a control. As shown in Fig. 3a, the $\mathrm{T}_{1}$ mapping signals in the heart were intensified significantly at $5 \mathrm{~min}$ after injection, and the intensified trend continued to reach a peak at $15 \mathrm{~min}$. After that, the signals became slowly weakened, while dark blue signals were still detectable at $30 \mathrm{~min}$ after injection of the contrast agent. Additionally, $\mathrm{T}_{1}$ mapping signals in the aortaventralis appeared to be strengthened during the initial $5 \mathrm{~min}$ after injection and the signal peak was reached at $5 \mathrm{~min}$. The degree of $\mathrm{T}_{1}$ mapping signal enhancement started to decrease after $5 \mathrm{~min}$, and at $30 \mathrm{~min}$ the signal was observed to reduce to the same level as that before injection (Fig. 3b). Furthermore, we performed quantitative analysis of $\mathrm{T}_{1}$ mapping images in the heart and aortaventralis via the $\mathrm{T}_{1}$ value. In the heart (Fig. 3c), the $T_{1}$ value increased in the initial few minutes after injection of the $\mathrm{mCA}$ and reached the enhancement peak at $15 \mathrm{~min}$. An increase by about $168 \%$ 


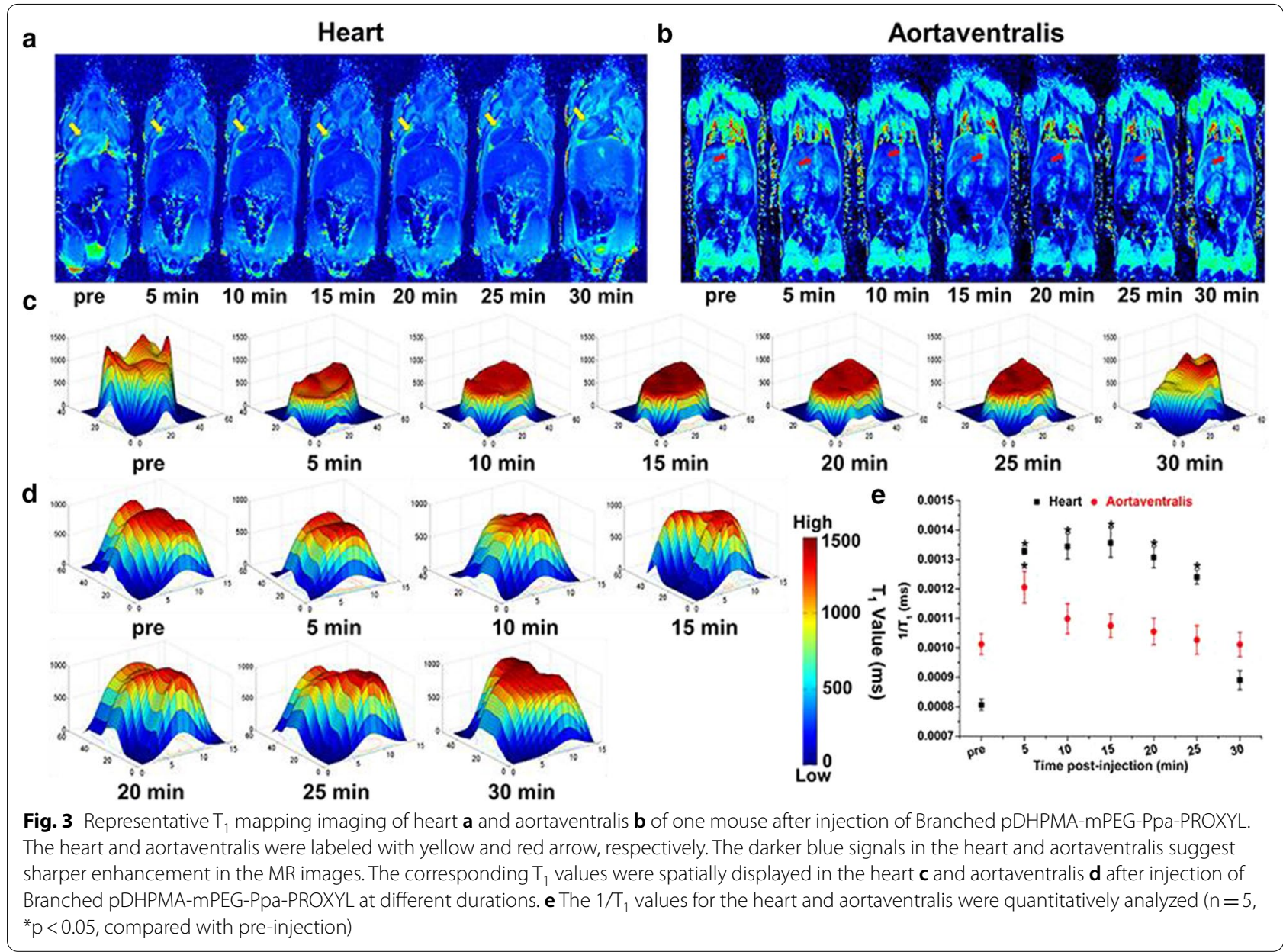

in the $T_{1}$ value was achieved in comparison with the level before enhancement (Fig. 3e). After $15 \mathrm{~min}$, the $\mathrm{T}_{1}$ value gradually decreased. The increasing pattern was also seen for the $T_{1}$ value in the aortaventralis (Fig. $3 \mathrm{~d}$ ), while the change gradient was much steeper and the value peaked at 5 min with an increase by about $120 \%$ compared to the level before enhancement (Fig. 3e).

In the liver (Fig. 4a), the $\mathrm{T}_{1}$ mapping signals began to increase and reached the enhancement peak at $5 \mathrm{~min}$ after injection. After $5 \mathrm{~min}$, the signals began to decline continuously, and recovered at the pre-injection level in $30 \mathrm{~min}$. The $\mathrm{T}_{1}$ mapping signals appeared to increase in the kidney (Fig. 4b) after $5 \mathrm{~min}$ and it reached an enhancement peak at $10 \mathrm{~min}$. The enhancement was noticed to last until $25 \mathrm{~min}$ after injection of the $\mathrm{mCA}$, and the signals returned to the pre-injection level at about $30 \mathrm{~min}$. Quantitative analysis of $\mathrm{T}_{1}$ mapping images in the liver and kidney via the $\mathrm{T}_{1}$ value. We found that the $T_{1}$ value in the liver (Fig. 4c) increased significantly within 5 min post-injection of the $\mathrm{mCA}$ and peaked at $5 \mathrm{~min}$ with the same trend as the $T_{1}$ mapping signals. The $T_{1}$ value was enhanced by about $137 \%$ compared to the level before enhancement (Fig. $4 \mathrm{e}$ ). The $\mathrm{T}_{1}$ value then gradually decreased and reduced to the pre-injection level at $30 \mathrm{~min}$. In the kidney (Fig. $4 \mathrm{~d}$ ), the $\mathrm{T}_{1}$ value increased to a peak at 10 min with an enhancement of about $136 \%$ compared to the level before enhancement (Fig. 4e). Both $\mathrm{T}_{1}$ mapping signals and the $T_{1}$ value in the organs (heart, liver and kidney) and aortaventralis displayed negligible changes after injection of 3-CP (Additional file 1: Fig. S6-S8). This can be explained as: (1) Branched pDHPMA-mPEG-Ppa-PROXYL has a higher relaxation efficiency in vitro; (2) Branched pDHPMA-mPEGPpa-PROXYL can form self-assembled aggregates with a larger particle size in the aqueous environment, and the hydrophobic nitroxides are encapsulated inside a hydrophilic outer layer of the self-assembled aggregates, so it can provide relatively long and stable MRI enhancement in the heart, liver, kidney and aortaventralis. At the same time, the $T_{1}$ mapping signals and $T_{1}$ value of the kidney increased, suggesting that Branched 


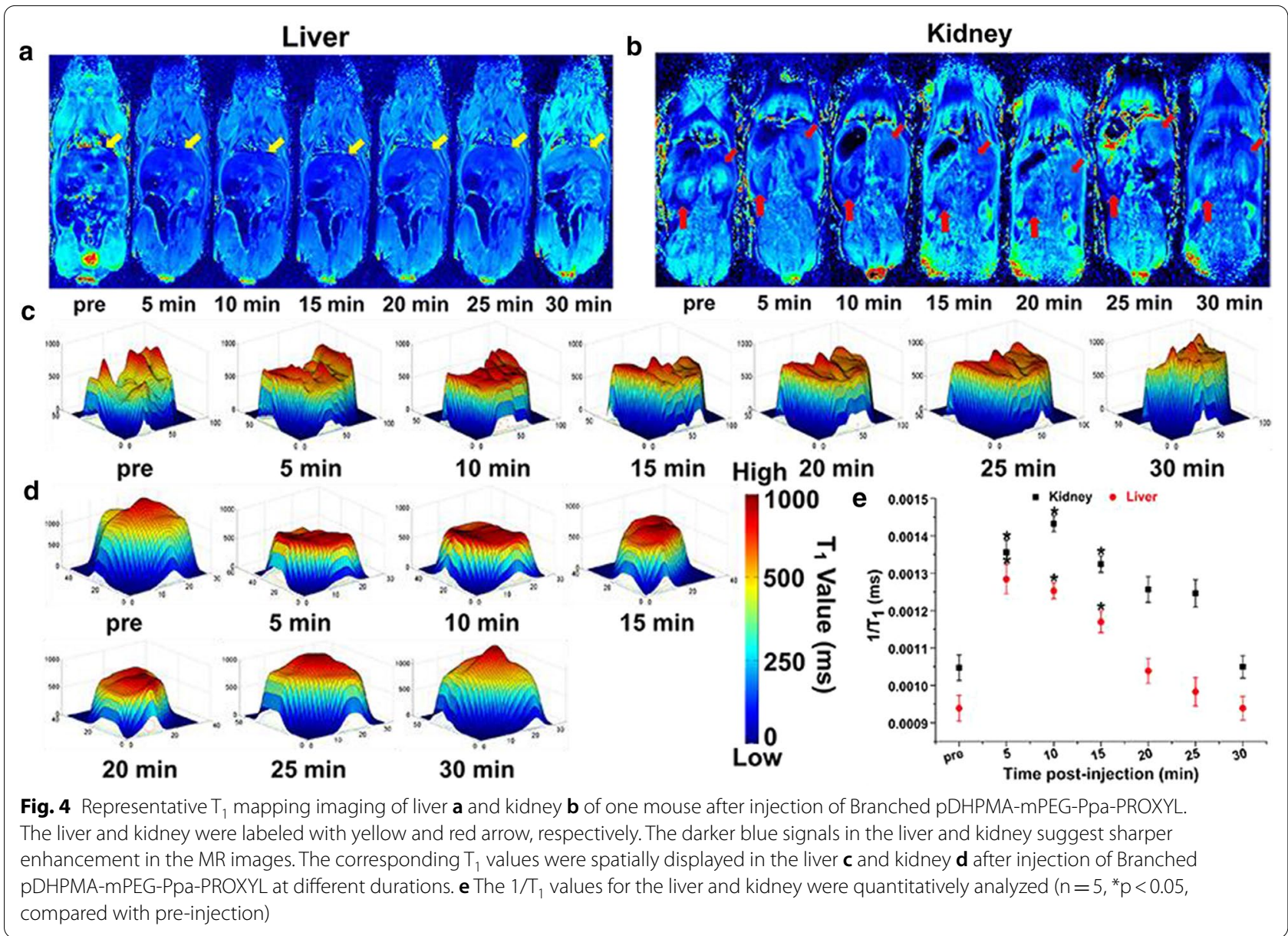

pDHPMA-mPEG-Ppa-PROXYL is mainly metabolized by the kidney, thereby ensuring its safety.

\section{In vivo tumor imaging}

Based on the above results from in vitro and in vivo MR imaging, we further studied the imaging efficacy of Branched pDHPMA-mPEG-Ppa-PROXYL at the tumor site. We also used $T_{1}$ mapping sequences to scan and observe the MRI enhancement in tumor-bearing mice at various time points. The imaging efficacy was quantified by $\mathrm{T}_{1}$ value, and 3-CP was also set up as a control group for the same scan.

After injection of the contrast agents, the $\mathrm{T}_{1}$ mapping signal at the tumor site began to strengthen within $5 \mathrm{~min}$ and reached the enhancement peak (Fig. 5a), and then began to decrease continuously, returning to the pre-injection level at $30 \mathrm{~min}$. Quantitative analysis of the above tumor $\mathrm{T}_{1}$ mapping images by $\mathrm{T}_{1}$ value (Fig. $5 \mathrm{~b}$ ) shows that Branched pDHPMA-mPEG-Ppa-PROXYL reached the enhancement peak of the tumor site at ca. $5 \mathrm{~min}$. The $\mathrm{T}_{1}$ value increased by about $144 \%$ (Fig. $5 \mathrm{c}$ ), showing a very high enhancement effect, this result was also consistent with the in vitro relaxivity results. After $5 \mathrm{~min}$, the $\mathrm{T}_{1}$ value gradually decreased and returned to the pre-injection level at ca. $30 \mathrm{~min}$. Subsequently, the small molecular 3-CP group was scanned by the same method as described above, and no significant increase in the $\mathrm{T}_{1}$ mapping signal at the tumor site was found (Fig. S9). It is known that the tumor tissue contains a higher concentration of reducing substances (such as GSH) than normal tissues, and this will seriously affect the MR imaging efficacy of Branched pDHPMA-mPEGPpa-PROXYL in tumors. However, the passive targeting ability to tumors and the protection of PROXYL by the amphiphilic structure allowed Branched pDHPMAmPEG-Ppa-PROXYL to provide a great MRI enhancement in tumor tissues.

\section{In vivo metabolism of PROXYL}

To measure the residence time of nitroxides released from Branched pDHPMA-mPEG-Ppa-PROXYL in the blood, we injected Branched pDHPMA-mPEG-PpaPROXYL and 3-CP as a control into normal mice via tail vein at a dose of $0.135 \mathrm{mmol} P R O X Y L / \mathrm{kg}$, and the blood 


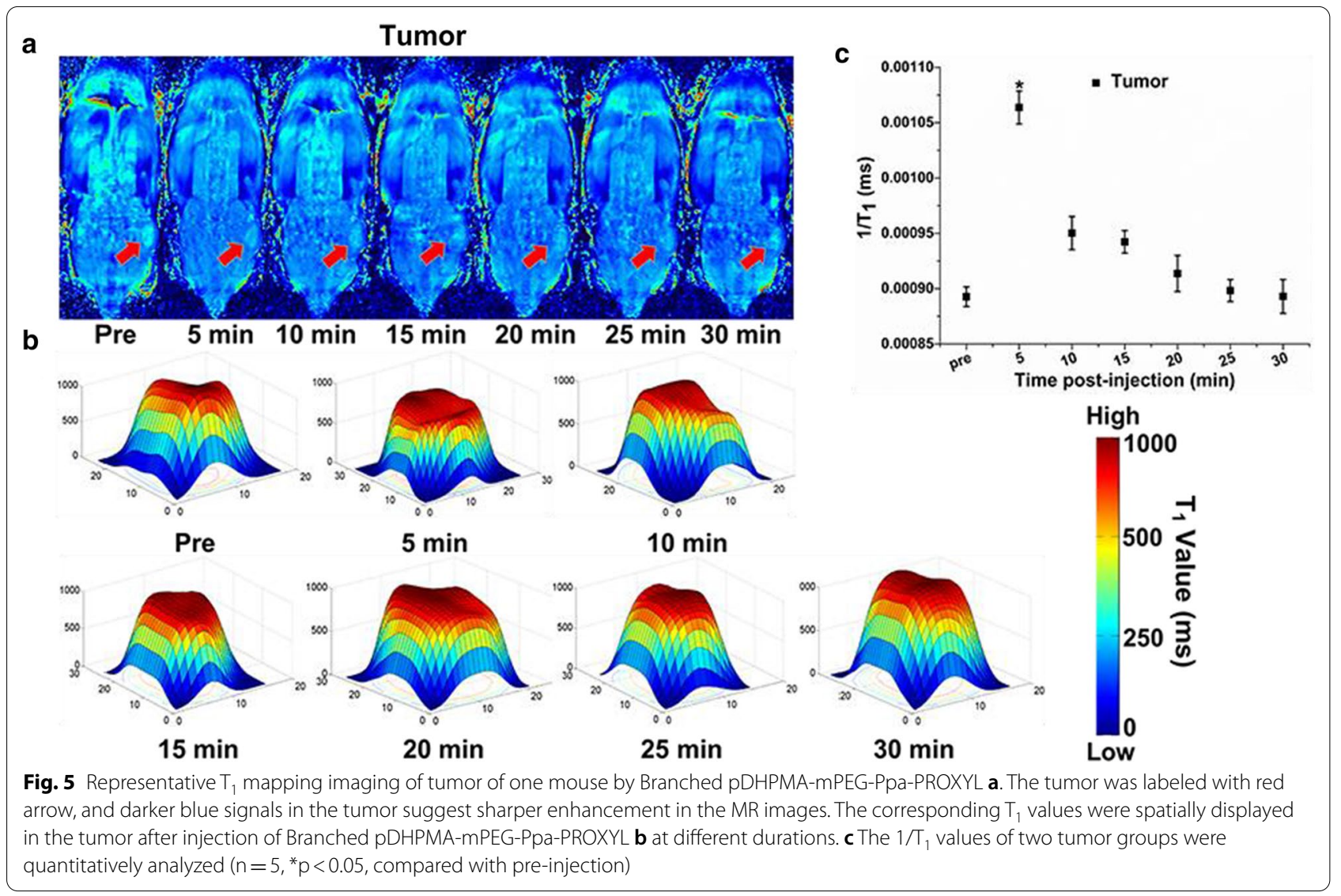

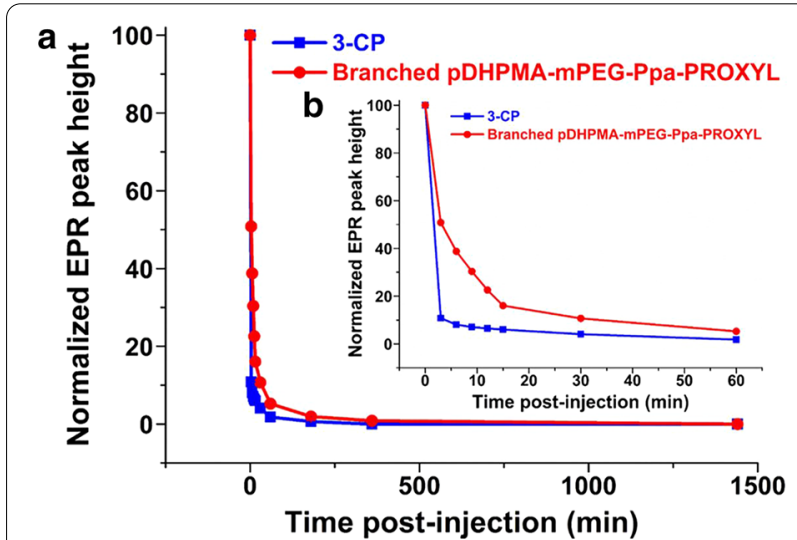

Fig. 6 a Nitroxides concentration distribution in vivo for $24 \mathrm{~h}$ after injection of Branched pDHPMA-mPEG-Ppa-PROXYL and 3-CP and $\mathbf{b}$ nitroxides concentration changes within $1 \mathrm{~h}$

samples at the same volume were collected at different pre-established time points to analyze the nitroxides concentrations in these blood samples by EPR.

The temporal changes of nitroxides concentrations in the blood of mice were shown in Fig. 6. It was observed that the PROXYL concentrations of $3-\mathrm{CP}$ in the blood rapidly decreased and they were below the detection limit at $1 \mathrm{~h}$ after the injection, indicating that the small molecule, 3-CP, was rapidly eliminated by reducing substances in the blood. However, the PROXYL concentration reduced much slowly in the Branched pDHPMA-mPEGPpa-PROXYL group. In the initial post-injection period, the nitroxides concentration was high and had more contact with reducing substances in vivo, therefore, the PROXYL concentration in the Branched pDHPMAmPEG-Ppa-PROXYL group displayed a similar decreasing trend as that in the $3-\mathrm{CP}$ group. However, as the concentration of nitroxides concentration gradually decreased, the macromolecular effects gradually started to become important, so the decreasing trend of nitroxides concentration became slower. As a result, the reduction rate of the nitroxides concentration in the Branched pDHPMA-mPEG-Ppa-PROXYL group was much less steeper than that in the 3-CP group, and the nitroxides were still detectable until $6 \mathrm{~h}$ after injection.

The macromolecular structure of Branched pDHPMAmPEG-Ppa-PROXYL plays a critical role in the extended circulation time of nitroxides: (1) The nitroxides are protected in the hydrophobic core of self-assembled aggregates, which results in a decrease in the interaction rate 
between endogenous reducing substances in the blood and nitroxides, thereby, nitroxides residues are still detectable up to $6 \mathrm{~h}$ post-injection; (2) As a macromolecule, Branched pDHPMA-mPEG-Ppa-PROXYL itself has a long blood retention time. A long blood retention time of Branched pDHPMA-mPEG-Ppa-PROXYL allows great accumulation of this $\mathrm{mCA}$ in the major organs, aortaventralis and tumor tissues, thus, enhancements of imaging contrast in these tissues/organs are achieved.

\section{Cellular uptake}

CLSM was used to study the uptake behavior and distribution of Branched pDHPMA-mPEG-Ppa-PROXYL in $4 \mathrm{~T} 1$ cells. It was observed that Branched pDHPMAmPEG-Ppa-PROXYL started to enter $4 \mathrm{~T} 1$ cells at $1 \mathrm{~h}$ after incubation, and the cytoplasmic fluorescence intensity at $6 \mathrm{~h}$ after incubation was significantly stronger than at at 1 and $2 \mathrm{~h}$ after incubation. Branched pDHPMAmPEG-Ppa-PROXYL accumulated in the cytoplasm (red fluorescence) and did not enter the nucleus (blue fluorescence) (Fig. 7). The experimental results showed that Branched pDHPMA-mPEG-Ppa-PROXYL could be taken up by $4 \mathrm{~T} 1$ cells and distributed in the cytoplasm without entering the nucleus, and the cells have a time-dependent behavior for the cellular uptake of this mORCA.

\section{In vitro cytotoxicity}

As shown in Fig. 8a, after incubation with Branched pDHPMA- mPEG-Ppa-PROXYL (from 0 to $1 \mathrm{mg} / \mathrm{mL}$ ) for $24 \mathrm{~h}$, the viability of $4 \mathrm{~T} 1$ and HUVEC cells showed no significant difference, and the concentration of PROXYL had negligible impact on the cell viability, which indicated that Branched pDHPMA-mPEG-Ppa PROXYL had no obvious toxicity to 4T1 and HUVEC cells. This could be due to a neutral surface charge of Branched pDHPMA-mPEG-Ppa PROXYL and a biodegradable macromolecular structure since the short peptide linker GFLG in the structure could be cleaved by cathepsin B in the cytoplasm.

\section{Blood compatibility evaluation}

We evaluated hemolysis induced by Branched pDHPMAmPEG-Ppa-PROXYL by observing the red blood cell (RBC) morphology via a SEM. As shown in Fig. 8b, after Branched pDHPMA-mPEG-Ppa-PROXYL at different concentrations was incubated with RBCs, the morphology of RBCs did not change significantly, and no red

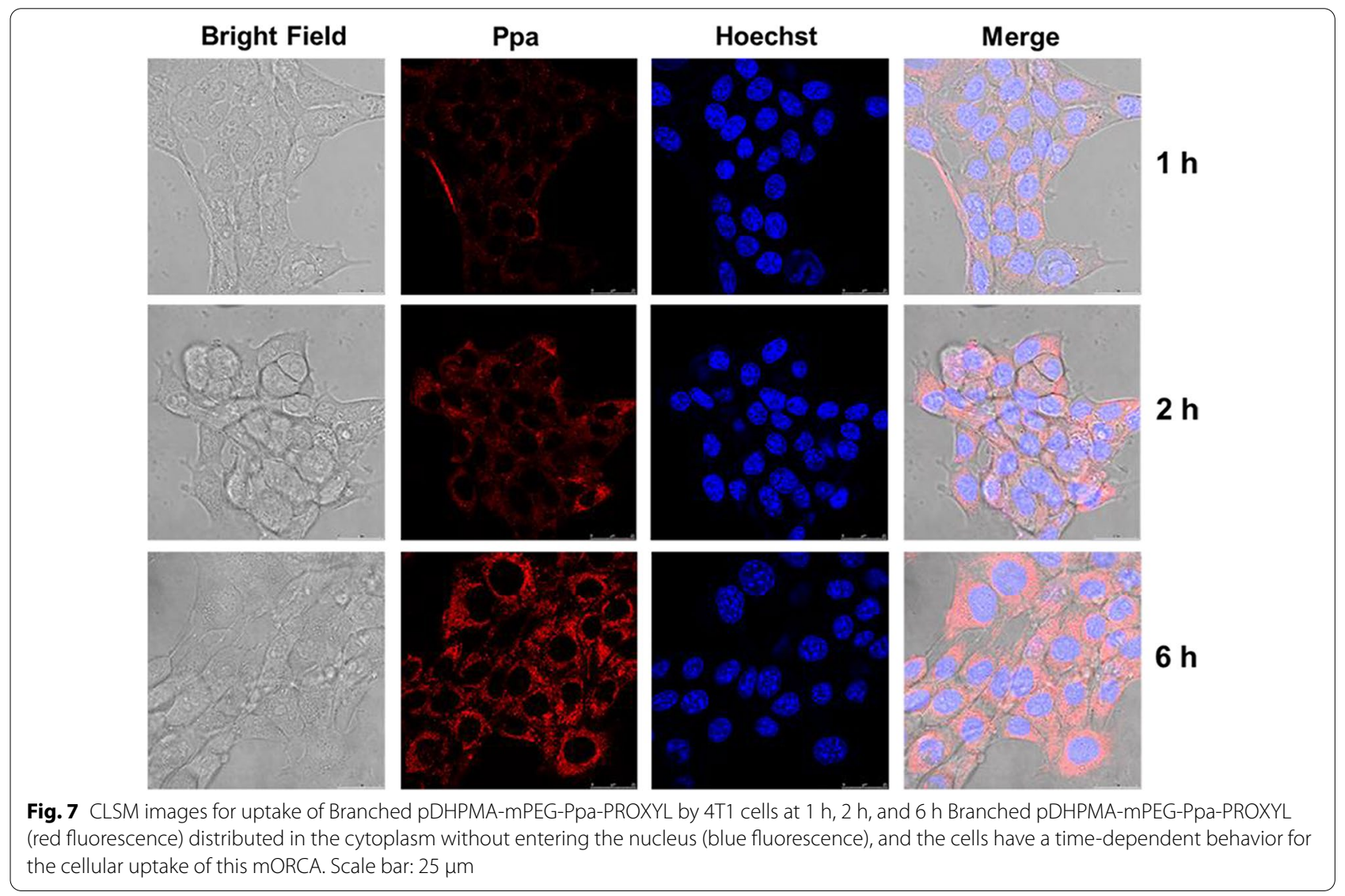




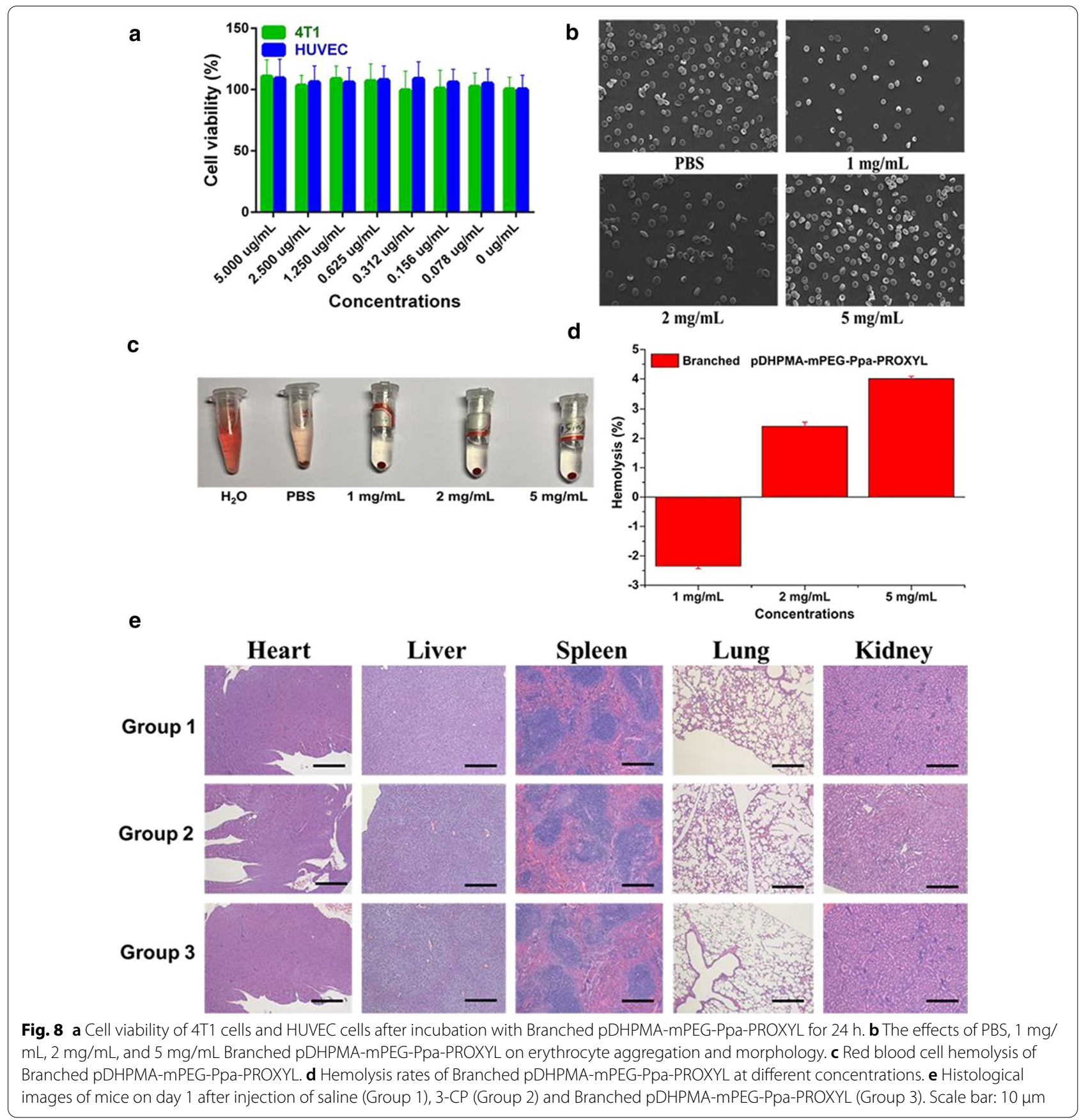

blood cells were aggregated. At a high magnification (1000x), the membrane surface of RBCs was smooth and intact with a normal biconcave disk-like structure. Compared with the PBS control group, there were no obvious changes with any abnormal structures such as collapse and rupture. Therefore, Branched pDHPMA-mPEG-PpaPROXYL did not cause any changes in the morphology and aggregation of RBCs and they had great biological safety.
After adding Branched pDHPMA-mPEG-PpaPROXYL to the whole blood, we measured the hemolysis with pure water and PBS as controls. The results showed that Branched pDHPMA-mPEG-Ppa-PROXYL did not cause hemolytic reaction at each concentration (Fig. 8c), which indicated that Branched pDHPMA-mPEG-PpaPROXYL had great blood compatibility and excellent biological safety. The degree of hemolysis is often quantified with the amount of hemoglobin released from 
RBCs after they are ruptured. The microplate reader was used to measure the absorbance of the sample at $540 \mathrm{~nm}$ because the absorption wavelength of hemoglobin is 540 $\mathrm{nm}$ and the hemoglobin content in the samples can be determined from the absorbance. The ASTM standards suggest that the hemolysis level for blood compatibility should be less than $5 \%$. After we incubated Branched pDHPMA-mPEG-Ppa-PROXYL at 1.0, 2.0 , and $5.0 \mathrm{mg} /$ $\mathrm{mL}$ for $12 \mathrm{~h}$, the hemolysis level at each concentration of the mCA was less than 5\% (Fig. 8d), and no significant difference was observed compared with PBS. Therefore, Branched pDHPMA-mPEG-Ppa-PROXYL had excellent blood compatibility.

\section{In vivo toxicity evaluation}

In order to evaluate the biological safety of Branched pDHPMA-mPEG-Ppa-PROXYL as a safe MR contrast agent, we further observed the toxic effect of the contrast agent in vivo. After $24 \mathrm{~h}$ of injection, the mice did not display obvious acute toxic and side effects (such as bleeding, motor ataxia, death, etc.). All these mice were killed and main organs (heart, liver, spleen, lung and kidney) were dissected for pathological analysis and blood samples were collected for routine blood and blood biochemical index analysis, such as RBCs, white blood cells (WBCs), hemoglobin (HGB), hematocrit (HCT), platelet (PLT), mean platelet volume (MPV), aspartate aminotransferase (AST), alanine aminotransferase (ALT), creatinine (CREA), alkaline phosphatase (ALP), glutamyltransferase (GGT) and blood urea nitrogen (BUN). The analysis results showed that compared with the 3-CP and saline control groups, no obvious tissue damage and abnormalities in histopathology (Fig. 8e) and blood chemistry indexes (Additional file 1: Figs. S11, 12) (such as inflammation, necrosis, atrophy, atrophy, tissue deformation, etc.) were seen in the mCA group. The experimental results indicated that at the MR imaging dose, Branched pDHPMA-mPEG-Ppa-PROXYL was non-toxic to the blood, organs and tissues of living animals.

\section{Conclusions}

Herein, we designed and prepared a water-soluble biodegradable branched polymeric nitroxides as a novel metalfree mCA (Branched pDHPMA-mPEG-Ppa-PROXYL) via covalently conjugation of a PEGylated PROXYL derivative onto an enzyme sensitive degradable branched pDHPMA. Its molecular weight (MW) and nitroxide radical content are $160 \mathrm{kDa}$ and $0.059 \mathrm{mmol} / \mathrm{g}$, respectively. Additionally, it is amphiphilic and can form a nanoscale $(\sim 28 \mathrm{~nm})$ self-assembled aggregate in a physiological environment, which is beneficial to prolong the circulation time in vivo; enhance the targeting of specific tissues (e.g. tumor); and reduce the contact between
PROXYL in hydrophobic core and reducing substances in vivo thus enhancing its stability. Thanks to the macromolecular effects and a higher nitroxides content, in vivo and in vitro studies showed that Branched pDHPMAmPEG-Ppa-PROXYL was superior to 3-CP in many aspects including the in vitro longitudinal relaxivity, in vivo stability of PROXYL and the MR imaging efficacy. At the same time, it did not show obvious toxicity in vivo. It should be pointed out that compared with all CAs of the same kind reported previously, Branched pDHPMAmPEG-Ppa-PROXYL could not only work in tumors and major organs (e.g. liver and kidney), but also provide MR imaging enhancements in the cardiovascular system. Therefore, Branched pDHPMA-mPEG-Ppa-PROXYL is a safe and efficient metal-free mCA for multi-object MRI in vivo. However, the in vitro relaxivity of Branched pDHPMA-mPEG-Ppa-PROXYL in this study is not high enough. The content of nitroxides in the macromolecular structure could be further increased without compromising its stable nanostructure in water environment, molecular weight and water solubility, thereby increasing the relaxivity of this $\mathrm{mCA}$, in order to achieve better contrast imaging of in vivo tissues.

\section{Abbreviations}

MRI: Magnetic resonance imaging; CAs: Contrast agents; mCA: Macromolecular contrast agent; 3-CP: 3-Carboxy-2,2,5,5-tetramethylpyrrolidine-

1-oxyl; pDHPMA: N-(1,3-dihydroxypropyl) methacrylamide copolymer; GSH: Glutathione; PEG: Polyethylene glycol; Ppa: Polyphthalamide; PBS: Phosphate buffer saline; TE: Echo time; TR: Repetition time; Fov: Field of view; EPR: Electronic paramagnetic resonance; SI: Signal intensity; CCK8: Cell Counting Kit-8; CLSM: Confocal laser scanning microscope; MW: Molecular weight; GFLG: Gly-Phe-Leu-Gly; PROXYL: 2,2,5,5-Tetramethylpyrrolidine-1-oxyl; TEMPO: 2,2,6,6-Tetramethylpiperidine-1-oxide; RBCs: Red blood cells; WBCs: White blood cells; HGB: Hemoglobin; HCT: Hematocrit; PLT: Platelet; MPV: Mean platelet volume; AST: Aspartate aminotransferase; ALT: Alanine aminotransferase; CREA: Creatinine; ALP: Alkaline phosphatase; GGT: Glutamyltransferase; BUN: Blood urea nitrogen.

\section{Supplementary Information}

The online version contains supplementary material available at https://doi. org/10.1186/s12951-021-00951-z.

Additional file 1: Scheme S1. Preparation of Branched pDHPMA-mPEGPpa-PROXYL. Table S1. Properties and characterizations of copolymers. Table S2. Contents of amino acids in the copolymers (wt\%). Fig. S1. ${ }^{1} \mathrm{H}$ NMR spectra of $\mathbf{a}$ Branched pDHPMA-SH and $\mathbf{b}$ Branched pDHPMAmPEG-Ppa-PROXYL (400 MHz, $d_{6}$-DMSO as solvent). Fig. S2. The EPR spectrum of Branched pDHPMA-mPEG-Ppa-PROXYL. Fig. S3. The particle size of Branched pDHPMA-mPEG-Ppa-PROXY (ca. 28 nm, DLS). Fig. $\mathbf{S 4 .}$ TEM images of Branched pDHPMA-mPEG-Ppa-PROXYL. Fig. S5. Zeta Potential of Branched pDHPMA-mPEG-Ppa-PROXYL (ca. 0 mV, DLS). Fig. S6. $T_{1}$ mapping of the heart after injection of 3-CP. Fig. S7. $T_{1}$ mapping ofthe aortaventralis after injection of 3-CP. Fig. S8. $T_{1}$ mapping of the liver and kidney after injection 3-CP. Fig. S9. $T_{1}$ mapping of the tumorsite after 3-CP injection. Fig. S10. MRI signals of Branched pDHPMA-mPEG-PpaPROXYL $\mathbf{a}$ and DTPA-Gd c. Fig. S11. Routine blood tests of mice treated with saline, 3-CP and Branched PDHPMA-mPEG-Ppa-PROXYL at 1 day post-injection. Fig. S12. Biochemical tests of micetreated with saline, 3-CP and Branched PDHPMA-mPEG-Ppa-PROXYL at 1 daypost-injection. 


\section{Acknowledgements \\ Not applicable.}

\section{Authors' contributions}

$\mathrm{XMW}$, SWG, KL: conception and design of the experiment, as well as manuscript writing; QL, YD: collection an assembly of data and data interpretation; $\mathrm{HZ}$ : edit the manuscript, support and discussions; XMW, SWG: perform the experiment; KL, ZQL, YY: technical and financial support; QYG: conception and design, financial support and the preparation. All authors read and approved the final manuscript.

\section{Funding}

This study was supported by the National Natural Science Foundation of China (51873120, 51673127, 81621003), 1·3·5 project for disciplines of excellence, West China Hospital, Sichuan University, China (ZYJC21013), the Open Project Program of Nuclear Medicine and Molecular Imaging Key Laboratory of Sichuan Province (HYX20006), Natural Science Foundation of Chongqing, China (cstc2019jcyj-msxmX0116), China Postdoctoral Science Foundation (2020TQ0212), Doctoral Research Startup Fund of the Affiliated Hospital of Southwest Medical University (19067), University level research fund of Southwest Medical University (2019ZQN026), The Collaborative Project of Luzhou Government and Southwest Medical University (2018LZXNYD-PT02).

\section{Availability of data and materials}

All data generated or analyzed during this study are included in this published article and its Additional file 1.

\section{Declarations}

\section{Ethics approval and consent to participate}

All animal experiments are conducted after obtaining ethical approval from the Institutional Animal Ethics Committee of the Sichuan University, Chengdu (No. 2018148 and 2018150 A).

\section{Competing interests}

\section{There are no conflicts to declare.}

\section{Author details}

${ }^{1}$ Huaxi MR Research Center (HMRRC), Department of Radiology, National Clinical Research Center for Geriatrics, Frontiers Science Center for Disease-Related Molecular Network, State Key Laboratory of Biotherapy, West China Hospital, Sichuan University, 610041 Chengdu, China. ${ }^{2}$ Functional and Molecular Imaging Key Laboratory of Sichuan Province, Research Unit of Psychoradiology, Chinese Academy of Medical Sciences, 610041 Chengdu, China. ${ }^{3}$ Department of Radiology, Chongqing General Hospital, University of Chinese Academy of Sciences (UCAS), No. 104 Pipashan Main Street, Yuzhong District, 400014 Chongqing, China. ${ }^{4}$ Department of Pharmacy of the Affiliated Hospital of Southwest Medical University, Southwest Medical University, Sichuan Province 646000 Luzhou, People's Republic of China. ${ }^{5}$ Nuclear Medicine and Molecular Imaging Key Laboratory of Sichuan Province, 646000 Luzhou, People's Republic of China. ${ }^{6}$ Amgen Bioprocessing Centre, Keck Graduate Institute Claremont, 91711 Claremont, CA, USA.

Received: 19 January 2021 Accepted: 1 July 2021

Published online: 09 July 2021

\section{References}

1. Lin SP, Brown JJ. MR contrast agents: physical and pharmacologic basics. J Magn Reson Imaging. 2007;25:884-99.

2. Barandov A, Bartelle BB, Williamson CG, Loucks ES, Lippard SJ, Jasanoff A. Sensing intracellular calcium ions using a manganese-based MRI contrast agent. Nat Commun. 2019;10:897.

3. Pellico J, Ellis CM, Davis JJ. Nanoparticle-based paramagnetic contrast agents for magnetic resonance imaging. Contrast Media Mol Imaging. 2019;2019:1845637

4. Gao Z, Ma T, Zhao E, Docter D, Yang W, Stauber RH, Gao M. Small is smarter: nano MRI contrast agents-advantages and recent achievements. Small. 2016;12:556-76.
5. Fu S, Cai Z, Ai H. Stimulus-responsive nanoparticle magnetic resonance imaging contrast agents: design considerations and applications. Adv Healthc Mater. 2021;10:e2001091.

6. Nguyen TDT, Marasini R, Rayamajhi S, Aparicio C, Biller D, Aryal S. Erythrocyte membrane concealed paramagnetic polymeric nanoparticle for contrast-enhanced magnetic resonance imaging. Nanoscale. 2020;12:4137-49.

7. Cheng CA, Chen W, Zhang L, Wu HH, Zink Jl. Magnetic resonance imaging of high-intensity focused ultrasound-stimulated drug release from a self-reporting core@shell nanoparticle platform. Chem Commun (Camb). 2020;56:10297-300

8. Wahsner J, Gale EM, Rodríguez-Rodríguez A, Caravan P. Chemistry of MRI contrast agents: current challenges and new frontiers. Chem Rev. 2019:119:957-1057.

9. Cao Y, Xu L, Kuang Y, Xiong D, Pei R. Gadolinium-based nanoscale MRI contrast agents for tumor imaging. J Mater Chem B. 2017;5:3431-61.

10. Israel LL, Galstyan A, Holler E, Ljubimova JY. Magnetic iron oxide nanoparticles for imaging, targeting and treatment of primary and metastatic tumors of the brain. J Control Release. 2020;320:45-62.

11. Zhang W, Liu L, Chen H, Hu K, Delahunty I, Gao S, Xie J. Surface impact on nanoparticle-based magnetic resonance imaging contrast agents. Theranostics. 2018:8:2521-48.

12. Vasanawala SS, Nguyen K-L, Hope MD, Bridges MD, Hope TA, Reeder SB, Bashir MR. Safety and technique of ferumoxytol administration for MRI. Magn Reson Med. 2016;75:2107-11.

13. Fretellier N, Granottier A, Rasschaert M, Grindel AL, Baudimont F, Robert $P$, Idée JM, Corot $C$. Does age interfere with gadolinium toxicity and presence in brain and bone tissues?: a comparative gadoterate versus gadodiamide study in juvenile and adult rats. Invest Radiol. 2019;54:61-71.

14. Thakor AS, Jokerst JV, Ghanouni P, Campbell JL, Mittra E, Gambhir SS. Clinically approved nanoparticle imaging agents. J Nucl Med. 2016:57:1833-7.

15. Nguyen HV, Chen Q, Paletta JT, Harvey P, Jiang Y, Zhang H, Boska MD, Ottaviani MF, Jasanoff A, Rajca A, Johnson JA. Nitroxide-based macromolecular contrast agents with unprecedented transverse relaxivity and stability for magnetic resonance imaging of tumors. ACS Cent Sci. 2017;3:800-11.

16. Jungmann PM, Agten CA, Pfirrmann CW, Sutter R. Advances in MRI around metal. J Magn Reson Imaging. 2017;46:972-91.

17. Mauri E, Micotti E, Rossetti A, Melone L, Papa S, Azzolini G, Rimondo S, Veglianese P, Punta C, Rossi F, Sacchetti A. Microwave-assisted synthesis of TEMPO-labeled hydrogels traceable with MRI. Soft Matter. 2018;14:558-65.

18. Celani A. Tempo is the key. Elife. 2020;9:e63385.

19. Lazarova D, Shibata S, Ishii I, Zlateva G, Zhelev Z, Aoki I, Higashi T, Bakalova R. Nitroxide-enhanced magnetic resonance imaging of kidney dysfunction in vivo based on redox-imbalance and oxidative stress. Gen Physiol Biophys. 2019;38:191-204.

20. Zhang X, Wu Y, Li Z, Wang W, Wu Y, Pan D, Gu Z, Sheng R, Helena T, Zhang H, João R, Gong Q, Luo K. Glycodendron/pyropheophorbide-a(Ppa)functionalized hyaluronic acid as a nanosystem for tumor photodynamic therapy. Carbohydr Polym. 2020;247:116749.

21. Zhang Y, Wang J. Targeting uptake transporters for cancer imaging and treatment. Acta Pharm Sin B. 2020;10:79-90.

22. Dobrynin S, Kutseikin S, Morozov D, Krumkacheva O, Spitsyna A, Gatilov Y, Silnikov V, Angelovski G, Bowman MK, Kirilyuk I, Chubarov A. Human serum albumin labelled with sterically-hindered nitroxides as potential MRI contrast agents. Molecules. 2020;25:1709.

23. Kim D, Le Q, Kim Y, Oh Y. Safety and photochemotherapeutic application of poly(Y-glutamic acid)-based biopolymeric nanoparticle. Acta Pharm Sin B. 2019;9:565-74.

24. Akakuru OU, labal MZ, Saeed M, Liu C, Paunesku T, Woloschak G, Hosmane NS, Wu A. The transition from metal-based to metal-free contrast agents for $T(1)$ magnetic resonance imaging enhancement. Bioconjug Chem. 2019;30:2264-86.

25. Rajca A, Wang Y, Boska M, Paletta JT, Olankitwanit A, Swanson MA, Mitchell DG, Eaton SS, Eaton GR, Rajca S. Organic radical contrast agents for magnetic resonance imaging. J Am Chem Soc. 2012;134:15724-7.

26. Garmendia S, Mantione D, Alonso-de Castro S, Jehanno C, Lezama L, Hedrick JL, Mecerreyes D, Salassa L, Sardon H. Polyurethane based 
organic macromolecular contrast agents (PU-ORCAs) for magnetic resonance imaging. Polym Chem. 2017;8:2693-701.

27. Chan JMW, Wojtecki RJ, Sardon H, Lee ALZ, Smith CE, Shkumatov A, Gao $\mathrm{S}$, Kong $\mathrm{H}$, Yang YY, Hedrick JL. Self-assembled, biodegradable magnetic resonance imaging agents: organic radical-functionalized diblock copolymers. Acs Macro Lett. 2017;6:176-80.

28. Nguyen HV, Detappe A, Gallagher NM, Zhang H, Harvey P, Yan C, Mathieu C, Golder MR, Jiang Y, Ottaviani MF, Jasanoff A, Rajca A, Ghobrial I, Ghoroghchian PP, Johnson JA. Triply loaded nitroxide brush-arm star polymers enable metal-free millimetric tumor detection by magnetic resonance imaging. ACS Nano. 2018;12:11343-54.

29. Soikkeli M, Horkka K, Moilanen JO, Timonen M, Kavakka J, Heikkinen S. Synthesis, stability and relaxivity of TEEPO-Met: an organic radical as a potential tumour targeting contrast agent for magnetic resonance imaging. Molecules. 2018;23:1084.

30. Guo S, Xiao X, Wang X, Luo Q, Zhu H, Zhang H, Li H, Gong Q, Luo K. Reductive microenvironment responsive gadolinium-based polymers as potential safe MRI contrast agents. Biomater Sci. 2019;7:1919-32.

31. Luo Q, Xiao X, Dai X, Duan Z, Pan D, Zhu H, Li X, Sun L, Luo K, Gong Q. Cross-linked and biodegradable polymeric system as a safe magnetic resonance imaging contrast agent. ACS Appl Mater Interfaces. 2018;10:1575-88.

32. Li H, Meade TJ. Molecular magnetic resonance imaging with gd(iii)based contrast agents: challenges and key advances. J Am Chem Soc 2019;141:17025-41

33. Cai H, Xiang Y, Zeng Y, Li Z, Zheng X, Luo Q, Zhu H, Gong Q, Gu Z, Liu Y, Zhang H, Luo K. Cathepsin B-responsive and gadolinium-labeled branched glycopolymer-PTX conjugate-derived nanotheranostics for cancer treatment. Acta Pharm Sin B. 2021;11:544-59.

34. Li J, Zhang X, Zhao M, Wu L, Luo K, Pu Y, He B. Tumor-pH-sensitive PLLAbased microsphere with acid cleavable acetal bonds on the backbone for efficient localized chemotherapy. Biomacromolecules. 2018;19:3140-8.

35. Guo S, Wang X, Dai Y, Dai X, Li Z, Luo Q, Zheng X, Gu Z, Zhang H, Gong Q, Luo K. Enhancing the efficacy of metal-free MRI contrast agents via conjugating nitroxides onto PEGylated cross-linked poly(carboxylate ester). Adv Sci (Weinh). 2020;7:2000467.

36. Chen K, Cai H, Zhang H, Zhu H, Gu Z, Gong Q, Luo K. Stimuli-responsive polymer-doxorubicin conjugate: antitumor mechanism and potential as nano-prodrug. Acta Biomater. 2019;84:339-55.
37. Dai Y, Ma X, Zhang Y, Chen K, Tang JZ, Gong Q, Luo K. A biocompatible and cathepsin B sensitive nanoscale system of dendritic polyHPMAgemcitabine prodrug enhances antitumor activity markedly. Biomater Sci. 2018;6:2976-86.

38. Gu Z, Luo K, She W, Wu Y, He B. New-generation biomedical materials: peptide dendrimers and their application in biomedicine. Sci China Chem. 2010:53:458-78.

39. Ou Y, Chen K, Cai H, Zhang H, Gong Q, Wang J, Chen W, Luo K. Enzyme/ $\mathrm{pH}$-sensitive polyHPMA-DOX conjugate as a biocompatible and efficient anticancer agent. Biomater Sci. 2018;6:1177-88.

40. Dai Y, Cai H, Duan Z, Ma X, Gong Q, Luo K, Gu Z. Effect of polymer side chains on drug delivery properties for cancer therapy. J Biomed Nanotechnol. 2017:13:1369-85.

41. Chen K, Liao S, Guo S, Zheng X, Wang B, Duan Z, Zhang H, Gong Q, Luo K. Multistimuli-responsive PEGylated polymeric bioconjugate-based nanoaggregate for cancer therapy. Chem Eng J. 2020;391:123543.

42. Wu Y, Li F, Zhang X, Li Z, Zhang Q, Wang W, Pan D, Zheng X, Gu Z, Zhang $\mathrm{H}$, Gong Q, Luo K. Tumor microenvironment-responsive PEGylated heparin-pyropheophorbide-a nanoconjugates for photodynamic therapy. Carbohydr Polym. 2020:255:117490

43. Zu G, Kuang Y, Dong J, Cao Y, Zhang T, Liu M, Luo L, Pei R. Gadolinium(III)based polymeric magnetic resonance imaging agents for tumor imaging. Curr Med Chem. 2018;25:2910-37.

44. Wang X, Guo S, Li Z, Xiao X, Gu L, Luo Q, Zhang H, Gong Q, Luo K. Safe and potent MRI contrast agents by complexing gadolinium with enzyme/reduction dual-sensitive branched polymers. Appl Mater Today. 2019:17:92-103.

45. Wu C, Xu Y, Yang L, Wu J, Zhu W, Li D, Cheng Z, Xia C, Guo Y, Gong Q. Negatively charged magnetite nanoparticle clusters as efficient $\mathrm{mri}$ probes for dendritic cell labeling and in vivo tracking. Adv Funct Mater. 2015:25:3581-91.

46. Li Z, Sun J, Hu X, Huang N, Han G, Chen L, Zhou Y, Bai W, Yang X. Assessment of liver fibrosis by variable flip angle $T_{1}$ mapping at 3.0T. J Magn Reson Imaging. 2016;43:698-703.

\section{Publisher's Note}

Springer Nature remains neutral with regard to jurisdictional claims in published maps and institutional affiliations.
Ready to submit your research? Choose BMC and benefit from:

- fast, convenient online submission

- thorough peer review by experienced researchers in your field

- rapid publication on acceptance

- support for research data, including large and complex data types

- gold Open Access which fosters wider collaboration and increased citations

- maximum visibility for your research: over $100 \mathrm{M}$ website views per year

At BMC, research is always in progress.

Learn more biomedcentral.com/submissions 